\title{
PI3K-gamma Inhibitor IPI-549
}

National Cancer Institute

\section{Source}

National Cancer Institute. PI3K-gamma Inhibitor IPI-549. NCI Thesaurus. Code C125471.

An orally bioavailable, highly selective small molecule inhibitor of the gamma isoform of phosphoinositide-3 kinase (PI3K-gamma) with potential immunomodulating and antineoplastic activities. Upon administration, IPI-549 prevents the activation of the PI3Kgamma-mediated signaling pathways, which may lead to a reduction in cellular proliferation in PI3K-gamma-expressing tumor cells. In addition, this agent is able to modulate anti-tumor immune responses and inhibit tumor-mediated immunosuppression. Unlike other isoforms of PI3K, the gamma isoform is overexpressed in certain tumor cell types and immune cells; its expression increases tumor cell proliferation and survival. By selectively targeting the gamma isoform, PI3K signaling in normal, non-neoplastic cells is minimally or not affected, which results in a reduced side effect profile. 